Article

\title{
Irritation Design: Updating Steering Theory in the Age of Governance
}

\author{
Marc Mölders \\ Faculty of Sociology, Bielefeld University, Germany; E-Mail: marc.moelders@uni-bielefeld.de
}

Submitted: 27 January 2021 | Accepted: 3 March 2021 | Published: 25 June 2021

\begin{abstract}
Is steering still a viable concept? The article answers this question with a conditional yes. On the one hand, its conceptual core remains intact. Getting others-who are considered to be idiosyncratic-to solve rather than pose societal problems is no less relevant for recent governance analyses. On the other, steering as a concept needs some updates in terms of subjects, objects, and ways of steering. Beyond merely extending the list of possible subjects and objects of steering, the concept of irritation design is proposed. It stresses that making communication hard to ignore can be a matter of design. Modern society seems to be crowded with steering entities, many of which displaying smart irritation designs. This leads to complex constellations. Yet it remains valuable to analyze strategies of influence because despite all dynamics and happenstance, different chances of impact correlate with different irritation design. Still, we have to account for two aspects: 1) Capacities (beyond money or power) needed for designing irritations are unequally distributed; 2 ) material effects and empirical boundaries have their share in a decreased ignorability.
\end{abstract}

\section{Keywords}

communication; control; environment; functional differentiation; governance; irritation; responsivity; steering; translation

\section{Issue}

This article is part of the issue "Steering in Governance: Evolutionary Perspectives" edited by Kristof Van Assche (University of Alberta, Canada / University of Bonn, Germany) and Raoul Beunen (Open University, The Netherlands).

(C) 2021 by the author; licensee Cogitatio (Lisbon, Portugal). This article is licensed under a Creative Commons Attribution 4.0 International License (CC BY).

\section{Introduction}

The governance paradigm has replaced steering theory (Bora, 2017). It questioned whether especially systemstheoretical design thinking "is still relevant to today's governance discourse and corresponding empirical analyses or, as a 'sunken cultural asset,' belongs more to the spectrum of the history of ideas" (Lange, 2007, p. 176, author's translation). Leaving uncommented whether the history of ideas could nevertheless be a place worth existing for concepts, the contribution at hand rather focuses on the question whether differentiation theoretical thinking can add something to understand current attempts at solving grand societal problems, such as environmental issues.

Evolutionary Governance Theory (EGT) is trying to strike a balance by using systems-theoretical design thinking and governance concepts complementarily. Inter alia, the paradigm change towards governance was claimed to be due to the growing importance of ever more players having a stake in collectively binding decisions. This adaptation to empirical conditions comes at a price which EGT aptly coined: "Part of the complexity is that other players anticipate each other's strategies, the direction of a collective strategy, and after enactment, do not stop strategizing" (Van Assche et al., 2020, p. 5). Thus, there are more players as well as elaborated sets of strategies which even take into account an environment full of other strategizing players. Instead of just calling this complexity and abandoning concepts of control, EGT remains interested in strategies. A strategy is defined as "a vision for a desirable longer-term future, coupled to an idea of how to get there" (Van Assche et al., 2020, p. 2). The contribution at hand proposes the concept of irritation design to systematically describe such ideas. The claim is: different degrees of effectiveness or chances of influence correlate with different irritation designs.

It starts by introducing a result special to differentiation theory: to conceive of societal differentiation as a 
cause for major societal problems as well as a reason for problems in tackling those issues (Section 2). The loss of a societal center of steering is one huge obstacle from this perspective. An even more severe aspect could be that such grand problems do not translate into action seamlessly. In order to become socially relevant, societal consequences have to be transformed from an irritation into information. As this observation is no less valid as in times preceding governance theory, the article does not conceive of differentiation theory as an outdated concept. Yet this leaves open whether this also applies to steering.

There are other authors, sharing a systemstheoretical point of view, who are no longer interested in steering, but propose to direct the view to 'responsivity,' i.e., to observe how autonomous systems respond to grand societal problems their environment poses. In this view, systems cause the need for correction and take over the correction of such self-produced problems. This perspective will be discussed under the heading of 'autocorrecting society' (Section 3).

Briefly summarizing three decades of differentiation theoretical steering concepts, Section 4 discusses different subjects, objects, and ways of steering. By focusing on how communications are prepared to make them hardly ignorable, irritation design goes beyond the previous literature. This concept is further illustrated along the three dimensions of meaning (factual, social, and temporal; Section 5).

In accordance with EGT, Section 6 concludes that it is worthwhile to focus on strategies and not to exclusively look for systemic responses toward grand societal problems. Another aspect that the concept of irritation design might benefit from is EGT's emphasis on the distinction between material and discursive effects. On the one hand, an ever-smarter irritation design by ever more entities might explain modern society's stability or inertia. On the other, we have to take into account that the ability to stimulate others to translate is unequally distributed in world society.

\section{Differentiation as Correction Cause and Correction Problem}

This contribution's first thesis is that steering deals with two different kinds of societal consequences of functional differentiation. The first one refers to "the incorrigible operational autonomy" of functional systems:

The best known is certainly the failure of the world economic system to cope with the problem of the just distribution of wealth....By focusing on schools and universities, the education system leads young people to spend far too long hanging around in institutions of higher education to improve career prospects, when they could long since have been married and in productive employment. Through the political parties, the political system attracts people into politics who then, merely because they have to keep busy, bestow unaffordable blessings on the nation. The expectations set in intimate relationships (under the heading of marriage for love) are now so heightened-because motives are, after all, needed for getting involved-that the ensuing marriages keep the therapists and divorce courts busy, and new attempts are frequent. (Luhmann, 2013, p. 124)

This means that a system's exclusive attention to its own processes has led to challenging consequences for themselves, but also, and at the same time, for society. Differentiation, specialization, and a focus on high performance equipped systems with blinkers that kept them from considering such societal consequences. As a result, corresponding societal environments can be "seen only as irritating noise, as disturbances or opportunities" (Luhmann, 2013, p. 66).

Luhmann distinguishes a second problem area that affects the environmental relations of society: ecological problems. Rather casually, an enlightening shift is taking place here. For it is no longer just a matter of differentiation as the cause of these problems, but rather of differentiation as an explanation for the difficulties in dealing with them, especially the lack of a central societal authority, it operates without apex or center (Luhmann, 2013, p. 125). Before dealing with societal problems such as environmental pollution there has to be a transformation of irritations into information, which is the task of each functional system (Luhmann, 2013, p. 126). Luhmann concedes that economy, science, or politics could be imposed to orient on such problems, especially if addressed by mass media or protest movements. But even successful imposition would not change the fact that each system reacted in its very own way: "politics rhetorically, the economy by raising prices, science with research projects, which with every advance in knowledge reveal still more ignorance" (Luhmann, 2013, p. 127).

The processing issue of both of Luhmann's problems due to functional differentiation's societal consequences - the formation of blinkers of systemic stubbornness and the lack of a central authority in environmental questions-is thus primarily based on the difference in functional systems' information processing. All irritations referring to societal problems only become information through functional systemic transformation, in this case then different information.

In terms of steering, there seems to be a crucial question: Can this transformation of irritations into information be triggered? Moreover, some accompanying questions come up: Is the level of functional systems the only relevant one? Who is irritating whom under what conditions-and how? Before we can turn to these questions, we have to acknowledge that there is a recent trend in differentiation theory that points into the opposite direction. Instead of asking how systems might be irritated, some scholars focus functional system's own 
preparations for societal problems. Therefore, I propose to call this development society's auto-correction.

\section{The Auto-Correction of Society}

Claiming society's auto-correction to be a recent trend might obscure that there have been corresponding contributions for a while. Dirk Baecker (1994) proposed to think of 'social work as a functional system' (Soziale Hilfe als Funktionssystem). He distinguishes between a primary and a secondary society. The former means functional differentiation. A secondary society is the result of functional differentiation and refers to the fact that large sections of a population are only concerned with survival, and that participation in the economy, politics, education, religion, art, or science is in any case blocked (Baecker, 1994, p. 95). Apparently, this diagnosis refers primarily to modern society's inclusion problems. The same society now responds to these problems by differentiating a functional system of social assistance. Without the consequences of functional differentiation, this system formation would not exist.

Correction phenomena are rather explained as the result of functional differentiation than to ask for how working on its consequences is stimulated: The functionally differentiated society not only creates its own problems; it also produces forms of correction that respond to these problems.

Responsivity is the latest conceptual development in this area. Rudolf Stichweh (2014, pp. 17-18) considers autonomy and purity semantics ('pure' and 'fundamental' science, 'l'art pour l'art,' etc.) and the formation of a collective singular (e.g., the law, the economy, etc.) to be essential for the beginning of differentiation processes. Formulas of autonomy and detachment were sought and found until it became a matter of course from the middle/end of the 18th century that science, for example, did not have to take other spheres (above all: religion) into consideration. This was followed by internal differentiation and thus a stabilization of autonomy - the formation of disciplines in the case of science (Stichweh, 1992).

After this phase of interior orientation, however, Stichweh (2014, pp. 17-18) identifies a 'trend change.' Functional systems, he argues, become responsive and expansive. In this sense, they want to be effective and important and they also want to be supported from the outside. Accordingly, systems incorporated a multitude of external perspectives, whose multiplicity was a guarantor of autonomy. Other functional systems and society as a whole are identified as the most important reference contexts (Stichweh, 2016, p. 11). It is understood as a consequence of functional differentiation that the functional systems themselves take major social problems into account. Where the impetus for the development of responsive structures and mechanisms comes from remains unresolved. Krichewsky (2021) asks for how problem formulations emerge and refers to ways of, and collectives involved in agenda-setting. But the identification and processing of problems encountered in other functional spheres still becomes reconstructed in terms of responsive systems, in his case as political responsiveness, leaving irritations unconsidered.

Such approaches ('auto-correction of society') seem to conceive of functional differentiation as an infinite cycle of self-produced problems and self-produced solutions related to them. Before the following section reverses the direction to focus on the stimulation aspect, a third way appears: Problems impose themselves physically.

Joren Jacobs and Kristof Van Assche (2014) pursue this very line with the concept of 'empirical boundaries.' These are defined as "boundaries that function as boundaries but do not originate in the internal semantics of the observing system" (Jacobs \& Van Assche, 2014, p. 194). Functional systems could, this is the conclusion, be irritated by spatial differences. 'Hit the wall' then denotes the moment of an irritation by the impact of 'hard boundaries.' The consequential problems discussed most thoroughly by Luhmann, ecological hazards, are exemplary here. For Jacobs and Van Assche, however, empirical boundaries describe all obstacles that "may be produced by the physical context without communication making any explicit reference to this matter of fact by means of boundary concepts. The empirical boundary... is a presocial (or post-social) boundary, existing in the environment of society" (Jacobs \& Van Assche, 2014, p. 199). Luhmann's (1989, pp. 28-29) well-known dictum thus appears as half the truth:

Fish or humans may die because swimming in the seas and rivers has become unhealthy. The oil-pumps may run dry and the average climatic temperatures may rise or fall. As long as this is not the subject of communication it has no social effect.

Where the environment does not impose itself (whether ultimately as a result of social or natural evolution remains to be seen), it only becomes a social phenomenon when it is communicated. But the other half would then include the assumption that physical or spatial aspects are able to impose themselves on a thematization. Marcelo Neves (2017, p. 393) drastically describes that social systems have a tendency to overload their environment with garbage: "Not only in the form of the wave of terrorism and global criminality does the garbage come back, but also, and above all else, through the uncontrollable refugee flows caused by war, hunger and oppression."

Even though this approach differs significantly in the dimension just described from other concepts discussed above, one common feature remains: Once again, it is not a matter of imposing a social (i.e., communicative) correction on society. The fact that exactly this kind of stimulation is needed, that one cannot rely on increased reflection capacities of autonomous 
systems, characterizes the following line of tradition of differentiation-theoretical steering concepts.

\section{Beyond the Limits of Steering}

One of the major obstacles posed by functional differentiation is that there is no central authority for dealing with its societal consequences. This configuration is worsened by a systemic autonomy that leads to the fact that every irritation pointing to social problems must be transformed into system-specific information. Luhmann's consequence was to emphasize "limits of steering." He defines steering as "a very specific use of distinctions, namely the attempt to reduce the difference" (Luhmann, 1997, p. 43). In order to move the economy closer to a politically preferred state, for instance, the political system can prohibit something, it can create costs, or the like. "When closely examining these possibilities one will probably establish that in most cases the point is to interfere in the relative attraction of the programmes" (Luhmann, 1997, p. 53). In short, a translation of originally political conditions into business-specific programs is likely if it (literally) pays off economically-if it is relatively attractive. In this case, however, it is still an economic program and this does not coincide with the political one. In the best case, both benefit: Politics can show success if pollutant levels improve after the implementation of a corresponding regulation and this is reflected in increasing voter favor. The economy can also score, for example if a company can strengthen its market position by presenting itself as a particularly green producer and this manifests itself in sales figures. Significantly, however, Luhmann (1997, p. 53) continues his argumentation in the opposite direction. Environmental regulations could also lead to the bankruptcy of certain companies. It is in this respect that this article aims to push the limits of steering.

In doing so, it joins the neighborhood of other authors who thought in a more constructive way about steering under the condition of functional differentiation. If operational autonomy and idiosyncratic information processing hinder dealing with the consequences of functional differentiation, reflection could be the key (Teubner \& Willke, 1984). With regard to dealing with functional differentiation's consequences, Helmut Willke (1992, p. 374) put forward that reflection:

Induces actors to realize that they cannot avoid being possible (that is: viable) environments of other systems. Reflecting this, systems may decide to restrict the range of their options to the few or even to the single one which complies with the conditions of productive-or at least non-destructive-systemenvironment-ecology.

Thereby, Willke specified steering (in his translation: guidance) in terms of an attempt to reduce a certain difference, namely reducing options to those complying with the system-environment-ecology. In other words, autonomous systems should be made to be a viable environment for other systems, and thus also to meet the overall system/environment interplay. But this is not expected to just happen or to be the next stage of functional differentiation, as the concept of responsivity assumes. Rather, this view must be the result of an irritation that was transformed into an information. There are countless communications that surround systems. Only a tiny fraction of it succeeds to become an irritation that is transformed into information. Consequently, it is even more unlikely for this information to stimulate a reflection which then, again, leads to productive (or at least non-destructive) outputs. What these remarks clearly show is that everything begins with an irritation. Systemstheoretical accounts continued this debate by asking who irritates whom in what way.

\subsection{The Who (Subjects of Steering)}

In the beginning, reflexive law is considered to be best equipped to provide mechanisms and procedures to induce reflection. Willke continues his thoughts by viewing the political system as a primus inter pares and in form of the 'supervision state' (Willke, 1997) or in terms of 'lateral world systems' (Willke, 2007). In his latest account, he proposes 'reflexive representation' (Willke, 2019): Special problems become delegated by elected parliaments to special senates made up of experts, e.g., central banks or regulatory agencies. Although the political system remains in charge, Willke (2014, p. 158; author's translation) recognizes a lot of helping hands: "Citizens' movements, committed NGOs, ecologically and sustainably oriented foundations, think tanks, expert committees and related institutions that think and act beyond national borders and are able to recognize and deal with global problems."

Teubner, too, embraces the extension of possible and already visible subjects of steering. He does not leave it at adding further players but emphasizes: "In no way are these extralegal mechanisms inferior to legal sanctions" (Teubner, 2011a, p. 37). In a globalized and digitalized world, steering theory should be aware that "societal forces are more relevant than nation states. Civil societal countervailing forces-the media, public debate, spontaneous protest, intellectuals, social movements, NGOs, trade unions, professions-exert considerable pressure on the internal constitutionalisation of transnational regimes" (Teubner, 2013, p. 51), their power pressures have proven to be crucial (Teubner, 2011a, p. 37).

At the beginning of systems-theoretical steering concepts, responsibility was clearly assigned to politics and/or law. Also due to the conditions of globalization and digitization, this clarity has given way to a much broader spectrum. But the fundamental question remains the same: How can stubborn systems be brought to reflection? With regard to the objects of steering, however, the tendency is more towards a narrowing. 


\subsection{The Whom (Objects of Steering)}

We also witness a remarkable shift regarding whose decisions are conceived of as most detrimental for the system-environment-ecology. In the beginning of systems-theoretical concepts of steering, it is all about self-referential systems in general. When it comes to examples, it is striking that it is expected that the objects of steering might strike (respectively: steer) back. On the one hand, the political welfare system can hardly escape the pressure to intervene in practically all societal domains (family, schooling, science, traffic, home building, energy consumption, etc.). "But also, the economy or religion, military, health, technology or other systems try hard to guide societal processes in an effort to intentionally change their respective societal environment in a preferred direction" (Willke, 1992, p. 374).

René Marcic, an Austrian philosopher of law, remarked as early as 1970 that in:

A constitutional state, everyone controls everyone else.....Not only 'state powers' but also other social powers are kept under control. This is a major problem of the contemporary state. Yes, even individual, particularly well-developed personalities, wealthy people or otherwise influential private individuals can exercise 'power' and must be controlled. (Marcic, 1970, p. 182; author's translation)

His list of possible controllers beyond the statebusiness associations, the scientific community, the church, the media of public opinion: press, radio, television, film, theater, cabaret-resembles Teubner's enumeration of civil societal countervailing forces. Whereas there is a consensus towards an extension on the subject side, we find an interesting focus on one societal context on the object side: The economy, to be precise, transnational corporations (Teubner, 2011a, 2011b). These are assumed to be particularly myopic and leading to extraordinary harmful societal consequences-which became even more visible after the last big financial crisis (Kjaer et al., 2011).

If we stick to the intuition that steering is a concept worth pursuing, it seems advisable to do both: 1) look for which societal context shows the deepest impact on the system-environment ecology; and 2) be open for possible objects of steering on any level and type of differentiation. In his pragmatist differentiation theory of translations, Joachim Renn (2006) proposes to add "integrative units" (Fuchs, 2009) underneath the abstract levels of functional systems and organizations, namely milieus and persons in terms of cultural differentiation. This leads to the assumption of a multiply differentiated society, meaning that there is functional as well as cultural differentiation which cannot be integrated by the means of one single type of coordination be it abstract-systemic or concrete-cultural. In a nutshell and with regard to the subject at hand, this means that even if an irritation is transformed into information by a functional system, it has to be re-specified by organizations. Within an organization, milieu's, and person's horizons interfere in concrete situations, translating the very abstract information coming from the level of functional systems. As an example, we might think of authorities or administrations with public access. Consider a law that directs compliance with climate targets, but then must be implemented in an administration by staff from a particular milieu and with a certain horizon of experience. This type of translation is called re-specification (Besio \& Meyer, 2015). Yet this process can take the other way around, starting in a concrete situation, maybe initiated by a single person, to become an explicit, standardized rule that organizations may increasingly generalize. But a cascade of translations can be expected in this direction as well. Multiple differentiation thus implies accounting for multiple subjects as well as objects of steering. In this perspective, civil societal countervailing forces are only a small part of the picture. In Marcic's terms this constellation-everyone controls everyone else-is the best a constitutional state can get. Pragmatist differentiation theory systematizes this 'everyone' into four integrative units: persons, milieus, organizations, or functional systems. We will revisit this in Section 5.

\subsection{The How (Ways of Steering)}

Finally, it does not come as a surprise that more than three decades of working on this particular perspective on steering also discussed different ways of making idiosyncratic systems reflect. When the law and the political system were seen in charge, it was searched for mechanisms and procedures, such as round tables. In any case, it seemed clear that they had to be interactions.

Again, taking into account the conditions of world society and media change led to a remarkable shift, this time with regard to the medium of steering attempts, in short: from face-to-face interactions to media-diffused communication. Especially if the target is to force transnational corporations to adapt their programs to be a viable environment, Teubner (2011a, p. 19) considers "the heavy public criticism globally disseminated by the media and the aggressive actions of protest movements and civil society, nongovernmental organizations (NGOs)" to be superior to the public codes of the state world. Reputation and 'public credibility' (Ku, 2000) are valuable currencies.

If the major objects of steering-entities following purely economic imperatives - can escape national laws by settling elsewhere, other means are required. This makes the shift towards public pressure as an essential source of irritation understandable. Summarizing these developments, there are many possible ways for many subjects to try to steer many objects. Yet there is one thing that remains unchanged: If it is all about making others reflect that continuing established routines can be disastrous for systems themselves as well as their social 
and natural environment, this has to start with an irritation. This does not mean to decide whether interactions or publicity rather bear reflexive capacities but to show a general interest in the process of making others reflect (Mölders, 2014, 2019). Moreover, neither any interactive format nor any type of publicity will equally suit this target. These differences call for considering design. And of course, opting for interaction or publication is not an aspect of choice for any irritating body. It may be easier than ever to publish communications. However, that is not equally true for getting the attention of sites deemed most relevant (Mölders \& Schrape, 2019).

The review of the development to the How-question can end here because this exact question is in the center of the now to be introduced concept of irritation design. This is still concerned with sounding out the possibility of steering without believing in direct transmissions without translation. What is new in this respect is, on the one hand, to focus on irritation as a necessary and formable first step and, on the other hand, to illuminate 'irritators' who already reckon with the impossibility of direct intervention.

\section{Designing Irritations}

If we stick to the postulate that autonomous systems can only be stimulated to make sense of communications that point to a change, the concept of irritation is at play:

In order to be open to irritation, meaning structures are built to form expectation horizons, which count on redundancies, hence with repetition of the same in other situations. Irritations are then registered in the form of disappointed expectations. Positive and negative... surprises can be involved. On both cases it is a matter, on the one hand, of momentary inconsistencies, which can also be forgotten; one sees the consequences or represses them. On the other hand, irritation can also assert its own repeatability and on this level runs counter to the expectation structures of the system. (Luhmann, 2013, p. 117)

This quote does not say anything about which characteristics communications must show in order to work as an irritation. From a constructivist perspective, there seems to be no other way; irritation is the condition of a different system, therefore there is no such thing as a direct intervention. However, the puzzling formulation is noticeable, irritations could assert their own repeatability. As puzzling as this statement may seem, it must be cases in which it becomes more difficult for a focused system to treat such communications as merely momentary inconsistencies. Exactly this is the anchor point for the concept of irritation design: to orientate communications at the expectation, to make it as difficult as possible for the addressee, to fade them out as situational and ignorable. How this can be made more difficult is the moment of designability.
In principle, corrections can start at any point in a translation cascade-persons, milieus, organizations, and functional systems. But sooner or later, correction requests end up on the attention screens of organizations. It need not stop at this principled argument. Instead, it can be argued that it is organizations where translation work is done. Besio and Meyer (2015) even argue that it is precisely organizations that mediate between different logics and can thus cushion differentiation consequences. External influences are segregated, filtered, and assimilated by organizations, which is addressed by the term re-specification introduced earlier. In this way, they make the incoming environment readable for themselves and, in turn, change and shape their environment.

The pragmatist differentiation theory calls organizations 'distribution heads' (Verteilerköpfe). In them, functional-systemic imperatives are worked into small pieces; in the opposite direction, it is organizations that ensure that impulses put forward by individuals or milieus are translated in a systemically generalizing way. This speaks for a special position of organizations for steering theory. Therefore, it does not come as a surprise that the exemplary sketches of the next sections all refer to organizations.

\subsection{Three Dimensions of Meaning: Factual, Social, Temporal}

The moment of repeatability already points to the temporal dimension. Timing seems to be an obvious aspect. If there is a massive global event, say, Olympics or the World Economic Forum, it may make sense to waitor, which belongs into the factual dimension, to connect a potentially irritating communication to this event. In very rare cases, one-off-communications succeed. It seems more promising to be persistent while not boring, which meant to be easily ignorable, again. As 'grand challenges' - such as the societal consequences of functional differentiation-are there to stay, any sort of solution that combines persistence with variation seems reasonable. For investigative journalism, to give an example of a recent countervailing force, this gets visible in cases of big leaks. As it is almost impossible to publish everything at once, journalistic consortia or comparable organizations may make a virtue of necessity by reminding of a topic at certain time intervals. This runs counter to the usual way of processing information in media organizations, to publish something as soon as possible and as long as it is a novelty, i.e., an information. Modern media ease to do that in a more interesting way, something might be best suitable for a podcast, for a blog, for a magazine, etc. Yet irritation design along the temporal dimension also means to account for the temporality of the focused system or addressee. For the political realm this might mean to synchronize one's own messages with election terms or the like.

In terms of the factual dimension, it seems reasonable to think of what Conversation Analysis coined 
'recipient design' (Sacks et al., 1974). This refers to compose communications along the expectation of what could be intelligible or readable for a focused addressee. We may associate this with attempts at translating one's own language into another, e.g., from a mass media language into a political dictionary. But we may also think of presenting communication in a way that is easier to digest. In order to convince lawmakers from limiting the power of big tech platforms, as investigative data journalist Julia Angwin from the tech watchdog organization The Markup puts it, one has to translate big data into 'small data,' i.e., providing them with concrete evidence of wrongdoing (Schwab, 2018). Teubner's (2020, p. 17) remark that irritations can also be aimed at the recognition of added or surplus values extends into the factual dimension, too. Such communications could, for instance, consider what is assumed to establish rather than to undermine public credibility.

How to reach lawmakers, is a crucial question for an irritation design that aims at making an addressee reflect to restrict the range of options to the few or even to the single one that an irritator sees in accordance with the common good. The way to get there leads to the social dimension of meaning. In this sense, structural couplings denote the ideal form (Luhmann, 2013, pp. 108-115). They are such firmly established intersystemic channels of interference that one can speak of "regular irritations" (Amstutz, 2013, p. 383). Communications can be relied upon to be delivered. The processing of scientific advice, for example, is then still subject to the filtering rules of politics. For journalism, for instance, there is no direct way to talk lawmakers into preferred changes. Therefore, they choose the medium of publicity to exert pressure, i.e., to make their communications hard to ignore. If the direct way is blocked, it must be about finding the shortest detour. Therefore, it can be of particular importance to find out what (public) communicative places a target (system) usually consults if in a state of uncertainty or just in search of valuable information. For some lawmakers, this might be a local newspaper with comparatively small print run, for judges this might refer to legal comments or journals. Furthermore, the social dimension can ask for who is considered to be a valuable coalition partner. This might be publication partners or persons sharing the same milieu as a relevant decision-maker.

All of this must not disqualify procedures taking the form of face-to-face interactions. Although not an option available to everyone, some entities can try to talk others into reflection in the above defined sense. Michael Hutter shed light on the microlevel of such formats. He notes that attracting attention of a self-referential entity means to find messages which become valuable information: "New information implies that the screen of the communicating system has to be conditioned in a way which makes it receptive to available new messages. Only the response of another system shows whether the attempt has been successful" (Hutter, 1992, pp. 271-273).
Making others reflect to choose an option not picked voluntarily, is obviously a tough business. The argument made in the preceding chapter does not mean to cast doubt on these difficulties but to acknowledge that irritation can be systematized not least by taking into account different temporalities and meaning processing rules. Because this is conceptually possible as well as empirically observable, the term irritation design was proposed. This concept is also suitable for explaining different chances of influence, e.g., when an irritation was incomprehensible, premature, or not even 'deliverable.' The concluding chapter will show that this solution sheds light on new problems, too.

\section{Conclusions}

The contribution at hand started by proposing steering to be an answer to the question how the societal consequences of functional differentiation could be tackled-and how this can be observed. Differentiation was claimed to be both, a cause of major societal problems as well as a major problem of working on them. If differentiation is displayed in many different kinds of information processing, it becomes clear that any communication that aims at working on such problems gets translated in very different ways and with very different consequences.

Therefore, some differentiation theoretical contributions turn the table and propose to rather look at systems' responses to problems originating elsewhere in society (without having been forced to). Because of the underlying assumption that systems start to work on problems caused by themselves, this line of research was called the auto-correction of society. In contrast to this, the point of departure for steering theory has always been that problems worsen if it is relied on systems' autonomy. The major question being how to make autonomous entities reflect to keep an eye on 'the big picture.' Explicitly, the assumption is that systems, at least, have to be triggered to do so.

To resurrect steering as a valuable concept, some means of modernization seem to be due. We have to account for several subjects of steering beyond the legal and the political system, be it from civil society, philanthropy, or a Fifth Estate in terms of networked citizens exerting pressure spontaneously, even disappearing when the issue is settled (Dutton et al., 2015, p. 19). Regarding the objects of steering, it seems advisable to assume many powerful instances of different sizes (from single persons to whole systems). If everyone controls everyone else (Marcic, 1970), things become ever more dynamic and therefore harder to control. Many steering subjects seem to be aware of that but to stop strategizing is not considered an option. It does not seem exaggerated to claim a 'control society' fueled by the rise of Big Data in terms of finding patterns in huge amounts of data which exceeds by far personal and organizational capacities (Elish \& boyd, 2018; Trish, 2018). 
Therefore, it seemed plausible to put forward the notion of irritation design and to focus on aspects of strategy. Even though autonomous addressees might only be irritated and never reached directly, making information more or less hard to ignore-this has been the bottom line-can be an aspect of design. While this might hold true for public relations or related sorts of strategic communication, too, the relation to steering comes in whenever an irritation design is led by the (regulative) idea to positively promote only those options out of an array of contingent possibilities that take into account future necessities, prerequisites or possibilities which comply with the conditions of the system-environment-ecology (Willke, 1992).

This emphasis on strategy is a shared concern for both EGT and the concept of irritation design. The latter is interested in communicative means able to trigger the transformation of irritations into information. Yet it can hardly be overseen that there are material effects which concern changes in the physical environment that seem to trigger communications (Van Assche et al., 2020, p. 6). Distinguishing between material and discursive effects is essential for the EGT perspective (Van Assche et al., 2014). The concept of irritation design stresses that problems do not draw attention to themselves automatically (or: naturally). Making others deal with problems (as big as the societal consequences of functional differentiation) is not left to chance alone but can be an aspect of design. Leaning on EGT, it can learn to be sensitive with regard to both directions: Not to underestimate the (organizational) work of making others reflect but also to consider the relevance of what EGT calls 'material effects.'

Control attempts already expect the control attempts of others and this reciprocal permanent observation would lead in the result to a far-reaching stabilization of present conditions. This implies a continuation of the systems-theoretical steering pessimism described at the beginning, which is not what we are aiming at here. What seems certain, though, is that no solution will prevail without irritation design. Even a supposedly irresistible solution idea does not flow barrier-free to implementation but has to pass through numerous translation stages. Viewed in this light, it seems hardly surprising that articles advocating the enforcement of technical solutions to address climate change, such as direct air capture, are at the very same time already considering methods of political persuasion (Hanna et al., 2021).

Further research should take into account that the capacity to stimulate others to translate is unequally distributed in the world society (Renn, 2006, p. 497). This inequality has not only to do with differences in power or money, but above all with how decisions are made about the use of power and money. The example of large-scale philanthropic organizations illustrates this particularly well (Mölders, 2020). Here, projects are monitored in such a targeted manner and their re-specification is controlled so systematically that the frequently described impacts of 'philanthrocapitalism' (Bishop \& Green, 2015) cannot be explained by power or money alone, but as an organizational effect (Mair \& Hehenberger, 2014; Reiser, 2018).

Moreover, it seems worthwhile to compare different irritation designs, e.g., along different societal contexts (science, arts, economy, religion, etc.), different guiding principles (evidence-based, technocratic, communitarian, etc.) or types of collectives (Dolata \& Schrape, 2018). All this also speaks in favor of taking an interest in strategies. It is easy to hint at strategies failing their targets. But this should not lead to overlooking impacts strategies-smart irritation designs-have.

\section{Acknowledgments}

I thank the editors for the invitation, Gunther Teubner for the recommendation, and the anonymous reviewers for their constructive criticism. In addition, an earlier version of the article benefited considerably from a colloquium discussion with Alfons Bora, Henning de Vries, and Eva Zimmermann.

\section{Conflict of Interests}

The author declares no conflict of interests.

\section{References}

Amstutz, M. (2013). Der zweite Text: Für eine Kritische Systemtheorie des Rechts [The second text: For a critical systems theory of law]. In M. Amstutz \& A. Fischer-Lescano (Eds.), Kritische Systemtheorie: Zur Evolution einer normativen Theorie [Critical systems theory: On the evolution of a normative theory] (pp. 365-401). transcript.

Baecker, D. (1994). Soziale Hilfe als Funktionssystem der Gesellschaft [Social help as a functional system of society]. Zeitschrift Für Soziologie, 23(2), 93-110.

Besio, C., \& Meyer, U. (2015). Heterogeneity in world society: How organizations handle contradicting logics. In B. Holzer, F. Kastner, \& T. Werron (Eds.), From globalization to world society: Neo-institutional and systems-theoretical perspectives (pp. 237-257). Routledge.

Bishop, M., \& Green, M. (2015). Philanthrocapitalism rising. Society, 52(6), 541-548. https://doi.org/ $10.1007 / s 12115-015-9945-8$

Bora, A. (2017). Semantics of ruling: Reflective theories of regulation, governance and law. In R. Paul, M. Mölders, A. Bora, M. Huber, \& P. Münte (Eds.), Society, regulation and governance: New modes of shaping social change? (pp. 15-37). Edward Elgar.

Dolata, U., \& Schrape, J. F. (2018). Collectivity and power on the Internet: A sociological perspective. Springer.

Dutton, W. H., Huan, S., \& Shen, W. (2015). China and the Fifth Estate: Net delusion or Democratic potential? IDP Revista De Internet Derecho Y Política, 20, 6-24. https://doi.org/10.7238/idp.v0i20.2648 
Elish, M. C., \& boyd, d. (2018). Situating methods in the magic of Big Data and Al. Communication Monographs, 85(1), 57-80. https://doi.org/10.1080/ 03637751.2017 .1375130

Fuchs, M. (2009). Reaching out; or, nobody exists in one context only: Society as translation. Translation Studies, 2(1), 21-40.

Hanna, R., Abdulla, A., Xu, Y., \& Victor, D. G. (2021). Emergency deployment of direct air capture as a response to the climate crisis. Nature Communications, 12(1), 368. https://doi.org/10.1038/s41467-020-20437-0

Hutter, M. (1992). How the economy talks the law into coevolution: An exercise in autopoietic social theory. In A. Febbrajo \& G. Teubner (Eds.), State, law and economy as autopoietic systems: Regulation and autonomy in a new perspective (pp. 265-293). Giuffrè.

Jacobs, J., \& Van Assche, K. (2014). Understanding empirical boundaries: A systems-theoretical avenue in border studies. Geopolitics, 19(1), 182-205.

Kjaer, P. F., Teubner, G., \& Febbrajo, A. (Eds.). (2011). The financial crisis in constitutional perspective: The dark side of functional differentiation. Hart.

Krichewsky, D. (2021). Political responsiveness: The identification and processing of problems in modern polities. In A. L. Ahlers, D. Krichewsky, E. Moser, \& R. Stichweh (Eds.), Global studies \& theory of society: Democratic and authoritarian political systems in 21st century world society-Vol. 1 Differentiation, inclusion, responsiveness (pp. 121-147). transcript.

$\mathrm{Ku}$, A. S. (2000). Revisiting the notion of "public" in Habermas's theory-toward a theory of politics of public credibility. Sociological Theory, 18(2), 216-240. https://doi.org/10.1111/0735-2751.00096

Lange, S. (2007). Kybernetik und Systemtheorie [Cybernetics and systems theory]. In A. Benz, S. Lütz, U. Schimank, \& G. Simonis (Eds.), Handbuch Governance: Theoretische Grundlagen und empirische Anwendungsfelder [Handbook of governance: Theoretical foundations and empirical fields of application] (pp. 176-187). Verlag für Sozialwissenschaften.

Luhmann, N. (1989). Ecological communication. Polity Press.

Luhmann, N. (1997). Limits of steering. Theory, Culture \& Society, 14(1), 41-57. https://doi.org/10.1177/ 026327697014001003

Luhmann, N. (2013). Theory of society: Volume 2. Stanford University Press.

Mair, J., \& Hehenberger, L. (2014). Front-stage and backstage convening: The transition from opposition to mutualistic coexistence in organizational philanthropy. Academy of Management Journal, 57(4), 1174-1200. https://doi.org/10.5465/amj.2012.0305

Marcic, R. (1970). Recht, Staat, Verfassung: Eine Einführung in die Grundbegriffe und in die österreichische Lebensordnung [Law, state, constitution: An introduction to the basic concepts and the Austrian order of life]. Österreichischer Bundesverlag für Unterricht, Wissenschaft und Kunst.
Mölders, M. (2014). Irritation expertise: Recipient design as instrument for strategic reasoning. European Journal of Futures Research, 2(1), 32. https://doi.org/ 10.1007/s40309-013-0032-3

Mölders, M. (2019). Die Korrektur der Gesellschaft: Irritationsgestaltung am Beispiel des InvestigativJournalismus [Correcting society: Irritation design by the example of investigative journalism]. transcript.

Mölders, M. (2020). Changing the world by changing forms? How philanthrocapitalist organizations tackle grand challenges. SocArXiv. https://doi.org/ 10.31235/osf.io/xh46a

Mölders, M., \& Schrape, J. F. (2019). Digital deceleration: Protest and societal irritation in the Internet age. Österreichische Zeitschrift für Soziologie, 44(1), 199-215. https://doi.org/10.1007/s11614-01900354-3

Neves, M. (2017). From transconstitutionalism to transdemocracy. European Law Journal, 23(5), 380-394. https://doi.org/10.1111/eulj.12259

Reiser, D. B. (2018). Disruptive philanthropy: ChanZuckerberg, the limited liability company, and the millionaire next door. Florida Law Review, 70(5), 921-970.

Renn, J. (2006). Übersetzungsverhältnisse: Perspektiven einer pragmatistischen Gesellschaftstheorie [Relations of translation: Perspectives of a pragmatist theory of society]. Velbrück.

Sacks, H., Schegloff, E., \& Jefferson, G. (1974). A simplest systematics for the organization of turn-taking for conversation. Language, 50(4), 696-735.

Schwab, K. (2018). How ProPublica became big tech's scariest watchdog. Fast Company. https://www. fastcompany.com/90160486/how-propublicabecame-big-techs-scariest-watchdog

Stichweh, R. (1992). The sociology of scientific disciplines: On the genesis and stability of the disciplinary structure of modern science. Science in Context, 5(1), 3-15. https://doi.org/10.1017/S0269889700001071

Stichweh, R. (2014). Differenzierung und Entdifferenzierung: Zur Gesellschaft des 21. Jahrhunderts [Differentiation and de-differentiation: On society in the 21st century]. Zeitschrift Für Theoretische Soziologie, 3(1), 8-19.

Stichweh, R. (2016). Inklusion, Differenzierung, Responsivität: Zu einer politischen Soziologie demokratischer und autoritärer politischer Regimes in der Weltgesellschaft des 21. Jahrhunderts [Inclusion, differentiation, responsivity: Towards a political sociology of democratic and authoritarian political regimes in the world society of the 21st century]. Unpublished manuscript. https://www.fiw.uni-bonn. de/demokratieforschung/forschungsprogramm_ langfassung

Teubner, G. (2011a). Self-constitutionalizing TNCs: On the linkage of "private" and "public" corporate codes of conduct. Indiana Journal of Global Legal Studies, 18(2), 17-38. 
Teubner, G. (2011b). A constitutional moment? The logics of 'hitting the bottom.' In P. F. Kjaer, G. Teubner, \& A. Febbrajo (Eds.), The financial crisis in constitutional perspective: The dark side of functional differentiation (pp. 9-51). Hart.

Teubner, G. (2013). The project of constitutional sociology: Irritating nation state constitutionalism. Transnational Legal Theory, 4(1), 44-58. https://doi. org/10.2139/ssrn.2419062

Teubner, G. (2020). The constitution of non-monetary surplus values. Social \& Legal Studies. Advance online publication. https://doi.org/10.1177/09646639209 52531

Teubner, G., \& Willke, H. (1984). Kontext und Autonomie: Gesellschaftliche Selbststeuerung durch reflexives Recht [Context and autonomy: Social self-control through reflexive law]. Zeitschrift für Rechtssoziologie, 6(1), 4-35.

Trish, B. (2018). Big Data under Obama and Trump: The data-fueled U.S. presidency. Politics and Governance, 6(4), 29-39. https://doi.org/10.17645/pag. v6i4.1565

Van Assche, K., Beunen, R., \& Duineveld, M. (2014).
Evolutionary governance theory: An introduction. Springer.

Van Assche, K., Beunen, R., Gruezmacher, M., \& Duineveld, M. (2020). Rethinking strategy in environmental governance. Journal of Environmental Policy \& Planning, 22(5), 695-708. https://doi.org/10.1080/ 1523908X.2020.1768834

Willke, H. (1992). Societal governance through law? In A. Febbrajo \& G. Teubner (Eds.), State, law and economy as autopoietic systems: Regulation and autonomy in a new perspective (pp. 353-387). Giuffrè.

Willke, H. (1997). Supervision des Staates [Supervision of the state]. Suhrkamp.

Willke, H. (2007). Smart governance: Governing the global knowledge society. Campus.

Willke, H. (2014). Demokratie in Zeiten der Konfusion [Democracy in times of confusion]. Suhrkamp.

Willke, H. (2019). Komplexe Freiheit: Konfigurationsprobleme eines Menschenrechts in der globalisierten Moderne [Complex freedom: Configuration problems of a human right in the globalized modern age]. transcript.

\section{About the Author}

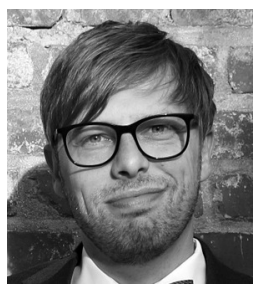

Marc Mölders has studied Sociology in Bonn, Bielefeld, and Edinburgh (Science \& Technology Studies). He works as a Senior Lecturer in the field of technology assessment and sociology of law at the Bielefeld Faculty of Sociology. His research topics include sociology of law, media, organization, technology, and sociological theory. He is interested in what concepts such as steering or control mean in a multiply differentiated society. 